Journal of Engineering and Applied Sciences 15 (6): 1431-1444, 2020

ISSN: 1816-949X

(C) Medwell Journals, 2020

\title{
Mural Paintings of the City of That Phanom: History and Literature
}

\author{
${ }^{1}$ Kittanut Yanpisit, ${ }^{2}$ Niyom Wongpongkham and ${ }^{3}$ Somsak Srisantisuk \\ ${ }^{1}$ Art and Cultural Research Program, Faculty of Fine and Applied Arts, \\ ${ }^{2}$ Faculty of Fine and Applied Arts, \\ ${ }^{3}$ Graduate School, Khon Kaen University, Thailand
}

\begin{abstract}
A research study titled mural paintings of the city of That Phanom: history and literature, aims to study the history of the making of mural painting in the city of That Phanom, as well as to study the literature of mural painting in the city of That Phanom. The study is based on historical documents and field studies in That Phanom district, Nakhon Phanom province of Thailand. Research tools consists of survey and structured interview, targeting group of informants consisting of scholars in art history, abbots and monks, local philosophers and local people. Study results showed that the history of the making of mural painting, currently existing in the city of That Phanom, Nakhon Phanom province, began in the year 1919-1934, coincided with the end of King Rama VI's reign and the beginning of King Rama VII's or during the transition from absolute monarchy to democracy. According the field study at three temples, the research witnessed important events related to the history of the creation of mural painting (Hoop taem) as follows. For Wat Hua Wiang Rangsi temple and Wat Buddhasima temple, construction of the uposathas (Sims) began in 1917; the two temples have royally been given the Visungkhamsima in 1919. For the making of the mural art, Wat Hua Wiang Rangsi's mural paintings were made in 1919 while that of Wat Buddhasima's, 1920; Wat Pho Kham's construction of Uposatha was in 1933 and the making of Hoop taem was first created in the year 1933-1934. Creation of Hoop Taem in the city of That Phanom all shared a starting point from the restoration of Phra That Phanom. In the period of Phra Khru Viroj Rattanobon who came from the city of Ubon Ratchathani, there was Luang Chan Akson who played the role as the painter, applying the concept of mural art of Bangkok style that had an influence on the Hoop taem of the city of That Phanom. Even they were built in the same period, each temple has a different identity. For the literature aspect, it can be divided into 2 groups: primary literary and secondary literary groups. The primary literary group used in the painting of Hoop taem consists of the Buddha's history, the Ten Jataka Tales, Sin Sai, Phra Malai and Suriyawong, of which the main literature shared in common is the Buddha's history. Each temple gives a lot of space for mural painting featured in a prominent position. The secondary literary group is the one that does not appear much, consisting of images of Ramayana, Laksanawong, Chantakorop and Phra Suthon-Manohra. The secondary literature that shares a common characteristic is the image of the Ramayana. According to each temple, it also shares different other literatures which are non-Buddhist, e.g., Ramayana, Sin Sai and Suriyawong, that became the outstanding literature of each temple.
\end{abstract}

Key words: Mural painting, Thailand, history, literature, prominent, applying

\section{INTRODUCTION}

North Eastern part of Thailand composes of two major civilization basins: Korat basin and Sakon Nakorn basin. There, various ancient communities scattered around the area, especially in Sakon Nakorn basin-a large civilization basin in the North or NE part covering provinces which are Loei, Nong Bua Lumpoo, Udon Thani, Beung Karn, Sakon Nakorn, Nakhon Phanom and Mukdaharn. Along the southern and west border is Phuphan mountain, separating Sakon Nakorn basin from Korat basin (Walliphodom, 1995). Based on archeological research, the study reveals that cultural development of Sakon Nakorn basin-Ban Chiang cultural tradition-which began near the end of a pre-historic era or around 5,000 years ago before Dvaravati culture slowly took over the society. Such is cultural evolvement during the beginning of Thai history between 14-16th BE Evidences found after the era shows that ancient Khmer or Khom culture had sprung up during 15-18th BE not long after the birth of Dvaravati culture. Evidence discovered within Sakon Nakorn basin indicates that ancient Khmer culture came into the area around the same time as Dvaravati culture did (Boonlop, 2005).

Once Khmer culture deteriorated, Sakon Nakorn basin became influenced by Lancang culture as can be seen in evidence found in Nong Khai, Udon Thani, Sakon

Corresponding Author: Kittanut Yanpisit, Art and Cultural Research Program, Faculty of Fine and Applied Arts, Khon Kaen University, Thailand 
Nakorn and Nakhon Phanom-stone inscriptions of Lancang King such as Phra Photi Sararaj, Phra Chai Shettiraj, Phrasumangkla Poitsat and Phrasuriya-Wongsa Thammikaraj. Such evidence indicated that Sakon Nakorn basin once belonged to Lancang Empire (Punnothok, 1988). Before the basin was permanently reigned by Siam in Thonburi era. Later, as a result of the colonial period, Lancang Empire was divided into two states. To the left of Kong river was that of Lancang, while the land to the right belonged to Siam.

Nakhon Phanom is a border province located in the upper North Eastern part of Sakon Nakhon basin and Lao PDR or the old Lancang Empire which are separated by Kong river. The province is around $740 \mathrm{~km}$ away from the capital-Bangkok. Most of the areas are low or plain land rests beside Kong river. The province's border runs along Kong river for $153 \mathrm{~km}$. Most of its land features are low land and river basins. Major rivers that flow through the province are Kong, Songkram, Kum, Ooun and Yaam rivers (GISTDA., 2010). Geographically, Nakhon Phanom has always been part or related to how history unfolds itself in other archaeological sites in Sakon Nakhon basin. The province is also connected to the outside through both land and sea. It also links to other historical sites in Lao PDR and Vietnam. Therefore, three ancient communities can be discovered in Nakhon Phanom-Songkram, Ooun-Yaam and Kum basin archaeological basins. Kum basin per se is considered a prominent archaeological site located in Nakhon Phanom. From the time after communities started forming in Dvaravati culture (around 13-16 BE.), historical communities, namely Sri-Kod-Boon city, began to flourish at the beginning of historical era near major estuaries. Important traces led to such fact is 'Phra That Phanom Statue', especially, the carved base of the Phra That statue. Thereafter, the community evolved into that of Lancang culture in 20-24 BE. Lancang culture extended its influence on Sri-Kod-Boon city until the reign of King Wisunarat (1999-2021 AD) (CDA and Archive, 1999). In 1778, during Thonburi period, the king decreed that Somdet Chao Phraya, king of war and Chao Phraya Surasi march an army to conquer the military of Vientiane due to Pra-war-pra-ta conflict. As a result, Vientiane became part of Siam. Land on both sides of the river was therefore, under the rule of Siam as well. In 2440 AD, colonialism of the world's then superpowersEngland and France-had spread to Thailand, causing Thailand to lose the land to the left side of Kong river to France. Lancang Empire then was split into two. During the reign of King Chulalongkorn the Great (Rama V), administrative regulations were westernized. Government administration system practiced in the border cities or burgs was divided into the precinct, province, district, sub-district and village. Nakhon Phanom is a minor border city within Lao-Puan Precinct. During the reign of King Rama VI, the king united different precincts into the region such as Northern, Northwest and Isaan regions. Viceroys were anointed as the administrative commanders who were to directly report to the king himself. Changing city to the province was another adjustment that happened in Nakhon Phanom. Besides being a large province, Nakhon Phanom also has a pillar of faith which highly revered by Thai people in the NE of Thailand and Lao PDR that is 'Phra That Phanom.

'Phra That Phanom' is situated in Muang That Phaom, That Phanom district, Nakhon Phanom province. Based on Urang-Ka-That legend, before the Buddha passed away, he came to 'Nong Khan Tae Sua Nam' with Ananda, the son of a god. The Buddha prophesized what will happen in the city (of Nakhon Phanom). The Buddha then traveled southward through various places along the Kong river. He finally, arrived at Sri-Kod city and rested at 'Poo Kampra'. Later on, the Buddha went to Nirvana for 8 years. During this time, Phra Maha Kassapa and 500 Buddhist saints or Arhats brought the Buddha's sternum or breastbone to and placed it at 'Poo Kampra'. For this reason, 'Phra That Phanom' had become the pillar of faith to the people in the area. It is a place of cultural recollection, since, pre-history period until present, containing local people's creativity expressed through their mural paintings-cultural local wisdom masterpiece that can be found in religious buildings. Based on a related study, it was found that mural wall paintings in NE of Thailand can be separated into 3 groups: one which was created by local craftsmen or artists, one which was influenced by Siam Royal Court and one which was influenced by Lancang. From a study exploring Isaan mural paints shooting project by Khon Kaen University (Samosorn, 1989), it was found that the mural wall painting was created before 2500 AD. in Nakhon Phanom mostly in 3 places: Wieng Rangsi temple in That Phanom sub-district, Puttasima temple in Fang Daeng sub-district and Poe Kum temple in Nam Kum sub-district. All three temples are considered prominent tourist attractions of That Phanom sub-district. Both state and private units have promoted them to be a local cultural learning center. Nevertheless, a lack of systematic study on all three temples has resulted in insufficient information to be provided to tourists and those who are studying art history and aesthetic study.

This study is therefore, conducted to delve into the history of That Phanom mural wall painting as well as looking into the literary works found in mural wall paintings in That Phanom by using the historical document. Unstructured interviews with historical experts, art historical experts, artists, painters, monks and local wisdom guru/philosophers were employed during the survey of mural painting in all three temples in That Phanom. The data collected from field surveys were then categorized chronologically and descriptive analysis was made in accord to the research objectives. 


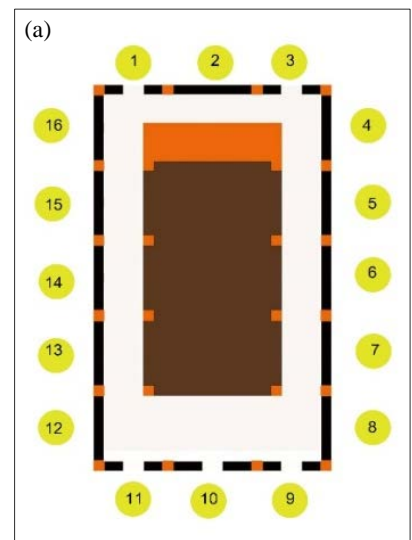

(b)

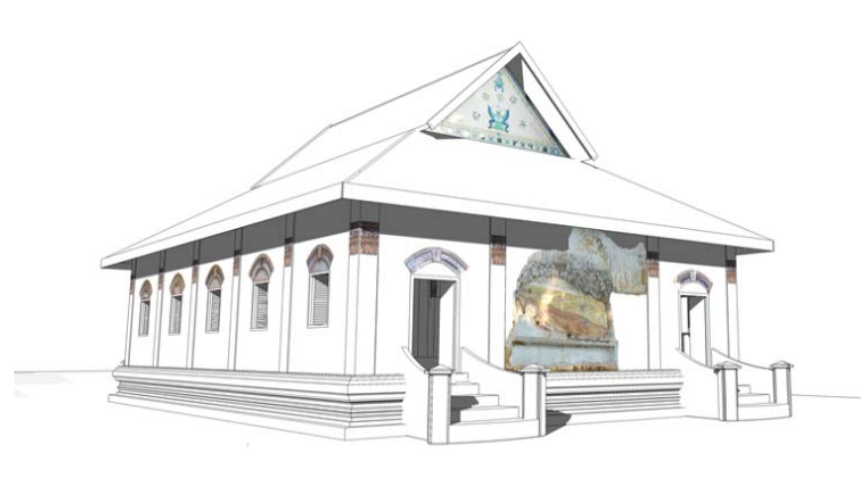

Fig. 1(a-b): Layout of mural painting on Hua Wieng Rangsi’s interior wall

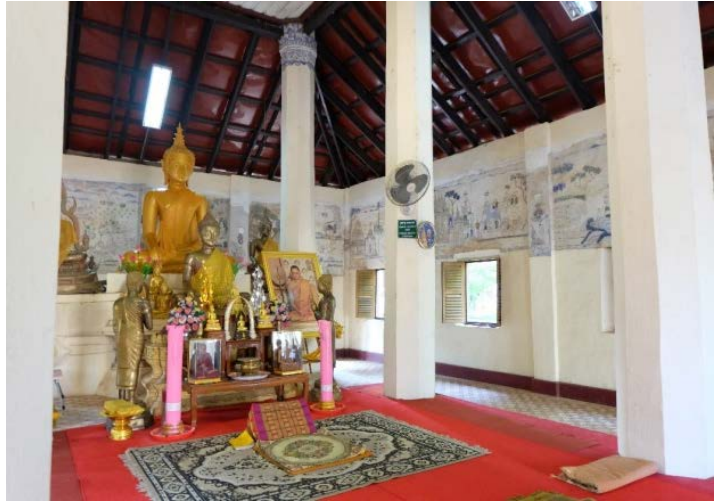

Fig. 2: Layout of Hua Wieng Rangsi’s interior wall

Literature review: A field study was employed to examine literature stories found in the mural painting of That Phanom district in Nakhon Phanom province. The data were collected through exploration and interviews. Below are the study results which are presented based on the location it was found in each temple.

From aesthetical point of view towards the mural paintings of That Phanom in Nakhon Phanom province, it was found that though mural paintings may had been painted around the same time, their identities are quite distinctive. Following are the summary of an aesthetic point of view towards its content and expression.

Aesthetic in the mural painting's content can be categorized into cannon literature and peripheral literature. The canon literary works found in mural paintings are the story of the Buddha, the 10 last Jatakas, Sinsai, Pra Malai and Suriwong. The common cannon literature they all share is the story of the Buddha. Each temple provides large spaces for mural paintings and cannon literature would be typically placed in positions that can be easily noticed. Peripheral literature, however is the ones of which stories were not included extensively in the mural paintings. These include the capture of
Ramayana, Laksanawong, Chantakrob and King Saud Thon-Manohra. Peripheral literature which can be commonly found in all temples are the Buddhism literature and the capture of Ramayana. Other differences found in each temple are literature which are neither the story of the Buddha nor the Ramayana. Such literature are Sinsai and Suriwong which became such outstanding literature for each of the temples.

Hua Wieng Rangsi, That Phanom sub-district, That Phanom district, Nakhon Phanom province: By surveying the mural painting on walls at Hua Wieng Rangsi temple in That Phanom sub-district, That Phanom district, Nakhon Phanom province, mural paintings were found both exteriorly and interiorly. Following are the details of the literature expressed through the mural paintings.

Exterior wall: It was found that literature told by artists who painted on the exterior wall of Hua Wieng Rangsi temple includes stories of the Buddha and other illustration. Since, the wall has only limited space, the artist did not intend to use such painting as the key story to be told. Appeared in the drawing are Indra, Buddha and Himmapan creatures. The purpose of this piece of art was done aesthetically than to express symbolistic meaning through the drawing.

Interior wall: The wall to the north of the temple tells 5 Jataka stories: Vedhura Pandita Jataka, Narada Brahma Jataka, Bhuridatta Jataka, Mahosadha Jantaka and Nemiraja Jataka. Painted on the wall to the East are Vessantara Jataka, the story of the Buddha and Ramayana. To the West, the artists also told of several literature stories: Ramayana, Temiya Jataka, Maha Jataka Jataka and Suvanna Sama Jataka.

From the examination of mural paintings on Hua Wieng Rangsi's interior wall, it can be summarized as can be seen in the layout below (Fig. 1 and 2): 

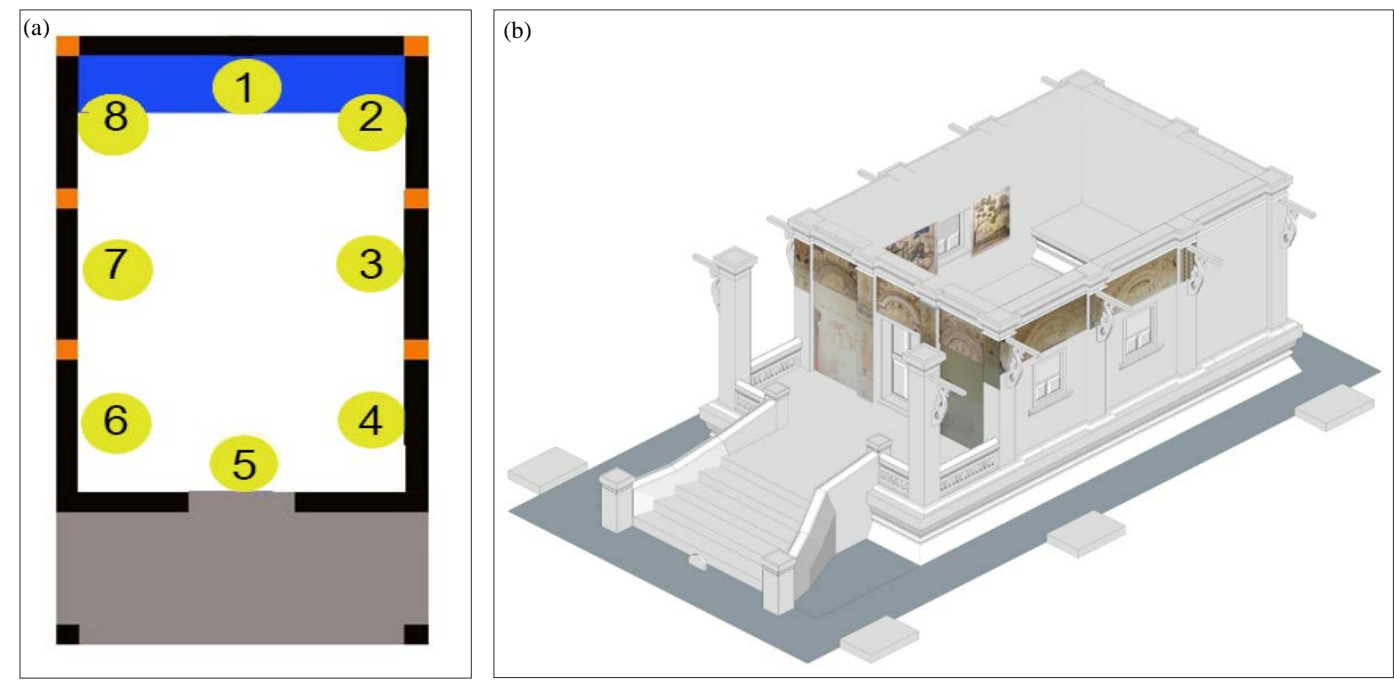

Fig. 3(a-b): Layout of mural painting on the interior wall of Phuttasima temple

Room 1 : Ramayana-the war of Ravana

Room 2 : Ramayana-the war of Ravana and Temiya Jataka

Room 3 : Maha Jataka and Suvanna Sama Jatakas

Room 4 : Nemiraja Jataka

Room 5 : Mahosadha Jataka

Room 6 : Bhuridatta and Chandakumara Jataka

Room 7 : Narada Brahma Jataka

Room 8 : Vedhura Pandita Jataka

Room 9 : Vessantara Jataka

Room 10 : Story of the Buddha

Room 11 : Ramayana Captures Sammanakka

Room 12: Ramayana-Rama hunt down a dear

Room 13 : Ramayana-Noksadayupaksi obstruct Ravana

Room 14 : Ramayana-the war

Room 15 : Ramayana-meeting of the war

Room 16: Ramayana-reservation of the road

Phuttasima temple, Fang Daeng sub-district, That Phanom district, Nakhon Phanom province: From the conducted survey on mural paintings of Phuttasima temple located in Fang Daeg sub-district, That Phanom district, Nakhon Phanom province, it is revealed that mural paintings are on both the exterior and interior walls. Mural paintings were found on the East and North side of the exterior wall but not on the South and West. Nevertheless, inside the temple, mural paintings could be found on all 4 walls. Literary works expressed through the mural paintings are presented in the following details:

Exterior wall: Literary works found in mural paintings on the wall to the north are a story about hell and Vessantara Tanaka. In the east, the story about the Buddha and Vessantara Tanaka is told in the mural paintings while in the west, the artists had drawn tales of Temiya Tanaka, MahaJataka Tanaka and Sinsai.

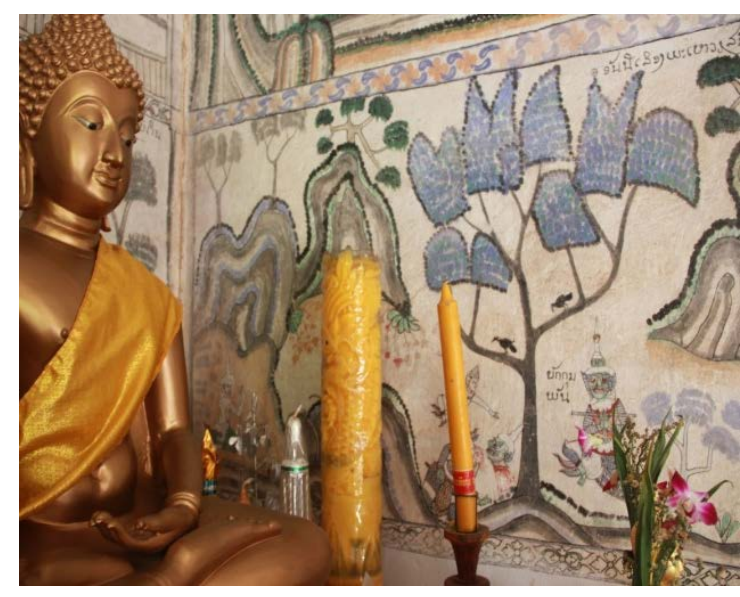

Fig. 4: Layout of mural painting found on the wall inside Phuttasima temple

Interior wall: As for the walls inside the temple, to the North are mural paintings which contain literary works about Vessantara Tanaka, Vedhura Pandita Tanaka, Narada Brahma Tanaka. On the lower part of the wall to the North are literary stories about Sinsai and King Saud Thon-Manohra. On the east side are stories about Bhuridatta Tanaka and Mahosadha Tanaka. The lower part of the wall are stories of Chantakorob and Sinsai. Written on the wall to the east in the upper part of the wall are Nemiraja Tanaka, Suvanna Sama Tanaka, Maha Jataka Tanaka and Temiya Tanaka. On the lower part of the wall, the artist illustrated tales of Sinsai. Painted on the west side of the wall is literature about the story of the Buddha and Sinsai literary work on the lower part of the wall. From the survey on the interior walls of Phuttasima temple, the layout can be summarized as in the Fig. 3 and 4. 

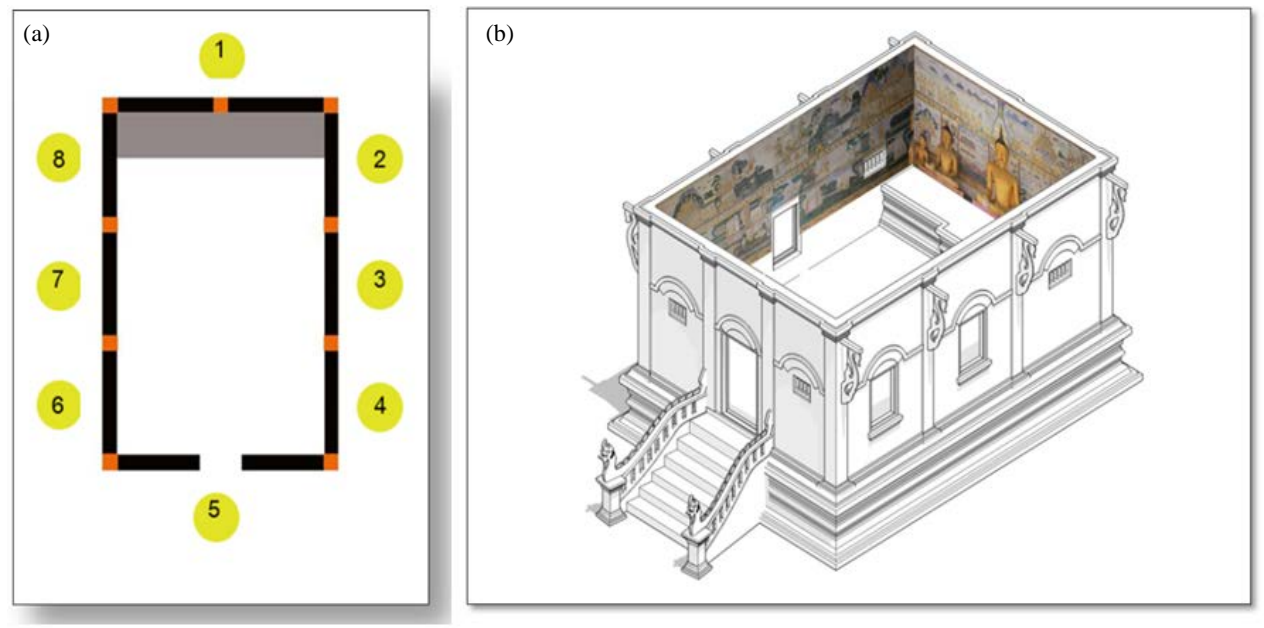

Fig. 5(a-b): Layout of mural paintings found on the inside wall of Phuttasima temple

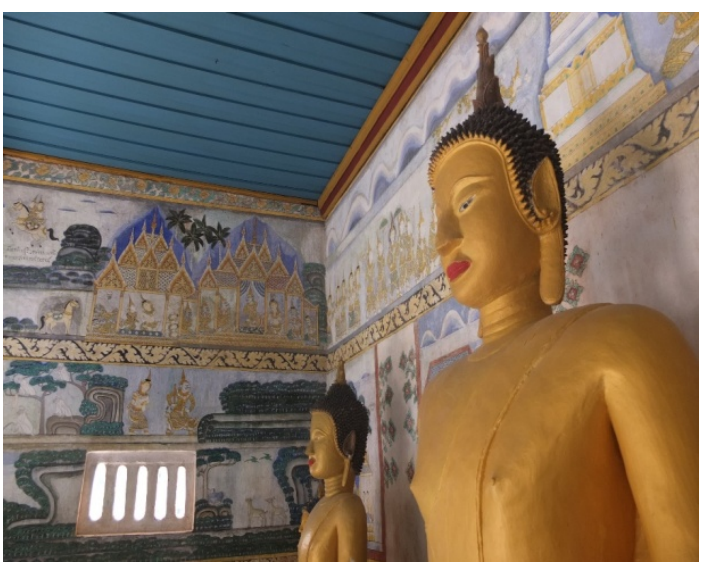

Fig. 6: Mural paintings inside Puttasima temple room 1 story of the buddha and sinsai

Room 2 : Vessantara Tanaka

Room 3 : Vedhura Pandita Tanaka, Narada Brahma Tanaka and story of Sinsai

Room 4 : Narada Brahma Tanaka and story about Sinsai

Room 5 : Chandakumara Tanaka, Bhuridatta Tanaka, Mahosadha Tanaka, Sinsai and Chatakorob

Room 6 : Nemiraja Tanaka and illustrations of soldiers

Room 7 : Suvanna Sama Tanaka, MahaJataka Tanaka and story of Sinsai

Room 8 : Temiya Tanaka and story of Sinsai

Poe Kum temple, Nam Kum sub-district, That Phanom district, Nakhon Phanom province: From the conducted survey at Poe Kum temple, Nam Kum sub-district, That Phanom district, Nakhon Phanom province, mural paintings were found only on the wall inside the temple. Illustrations are found on all four walls of which literary works are expressed as in the details below:

Wall to the North: The upper part of the wall told the story about the Buddha with chronological order-the story started in the upper part of the wall and continue to the lower part of the wall.

Wall to the East: Found on the upper part of the wall are the story of the Buddha, Suriwong and the capture of Ramayana.

Wall to the South: Drawn on the entire wall is the literary work called Suriwong from the top to the bottom of the wall.

Wall to the West: Painted on the top of the wall are literary work called 'Pra Malai-Dhamma talk with Indra' and 'paying respect to Ket Kaew Chula Manee Stupa and Dhamma talk with Prasri Maitreya. Some portion of the wall tells a story of the Buddha. On the bottom of the wall is the story of 'Pra Malai-Poor boy offering lotus flower' and 'Pra Malai-A Visit to Hell'. From the survey, the studied mural paintings are laid out as can be seen in the plan below Fig. 5 and 6 .

Room 1 : Story of 'Pra Malai' and the 'Buddha'

Room 2 : Story of the Buddha

Room 3 : Story of the Buddha

Room 4 : Story of the Buddha

Room 5 : Story of the Buddha, capture of Ramayana and Thao Suriyawong

Room 6 : Story of Thao Suriyawong

Room 7 : Story of Thao Suriyawong

Room 8 : Story of Thao Suriyawong 


\section{MATERIALS AND METHODS}

History: Documentary research and field study was employed in this research on the history of That Phanom mural wall painting in Nakhon Phanom province. Data were collected using interviews and survey. Data being presented involve background information of the community, temples and mural painting on walls found at Hua Wieng Rangsi temple, Puttasima temple, Poe-kam temple. The study results reveal that:

Hua Wieng Rangsi temple, that Phanom sub-district, that Phanom district, Nakhon Phanom province: Hua Wieng Rangsi temple is situated in the old community. The community used to hold the title as 'Monastery Serf's who entitled to look after Phra That Phonom and being exempt from paying taxes to the royal court. Wat Hua Wieng is located in the upper area of the community beside Kong river. The place serves as an important port in trading and exchanging goods of That Phanom city.

Hua Wieng Rangsi is situated in Wat Hua Wieng. It is a Thammayuti Nikai temple. Rests around $2 \mathrm{~km}$ away from Phra That Phanom are ports which are used to exchange goods. The new Isaan temple where the mural painting is found was built in replacement of the deserted one. The temple faces eastwards to the Kong river which was then the main route people used to commute. The temple was constructed in the style called 'Song Rong' using bricks before being plastered with stucco. It was presumed that the temple was built by Vietnamese construction workers in around 2460-2462 AD. 'Visungkamsima' was given on 19 January, 2462 AD. From the temple which was built with 'Song Rong' style, it later adopted features seen in temples situated in the lower NE and adjusted to a more contemporary style when That Phanom was restored for the fifth time in 2444 AD by a monk named Wirote Ratnobol from Tung Sri Muang temple in Ubon Ratchathani.

The discovered mural painting was created around 2462-2463 AD. by an official named Luang Chan Aksorn with local artist, Ajarn Koon and Janlee. Luang Chan Aksorn was the painter who used to paint mural painting on the wall of Tung Sri Muang temple in Muang Ubon Ratchathani province. He was persuaded by Monk Wirote Ratanobol to assist with the 5th restoration of Phra That Phanom since, 2444 AD. Jankoon and Janlee, however were the local artists from That Phanom city. It is therefore, believed that the mural paintings in this temple were created by various artists.

Puttasima temple, Fang Daeng sub-district, That Phanom district, Nakhon Phanom province: Ban Fang Daeng which is located in Fang Daeng sub-district is around $6 \mathrm{~km}$ away from That Phanom municipality. People first migrated from Laos (situated on the left to Kong river) around $2384 \mathrm{AD}$ to flee from 'Haw War'.
They settled on the bank of Nam Kam (river) and named the village 'Ban Fang Daeng', since, there were a lot of 'Mark Daeng' trees (Sealing wax palm) and also because of the fact that both sides of the river were covered in red soil. The community is an old community which holds a position called 'Monastery Monk'. Monastery monks are entitled to look after Phra That Phanom and are exempted from paying taxes to the royal court. Wat Hua Wieng community is established in the upper part of Rim Nam Kam community which is $6 \mathrm{~km}$ away from Kong river. For this reason, this community is important strategically, since, it connects with Sakon Nakhon-the headspring of the river and That Phanom city which is at the mouth of Kong river.

Puttasima temple was established on 1st January, $2308 \mathrm{AD}$ it was given consecrated boundaries on 15th January 2462 AD (DRA, 1996) The temple with discovered mural painting was constructed in a stifling style. The size with a size of about 3 rooms with 1 porch on the front. The base is decorated with 1 row of pointed torus moulding base. Two windows are placed on each side-one window per room, except in the west where the last room is situated. Principle Buddha image is enshrined in this room with no window. The front of the temple faces eastward. At the entrance is the staircase which resembles a bell like that of Europe-a style popular among Vietnamese craftsmen. It is ascribed that the temple was built before it was given consecrated boundaries around 241-2462 AD., around the same time when Hua Wieng Rangsi was established in That Phanom sub-district, That Phanom district, Nakhon Phanom province.

The mural painting was created around $2463 \mathrm{AD}$ by a craftsman named Mr. Kumsing Chaiyo (DRA., 1996). Nevertheless, Samosorn, (1989) stated that the painters include Jankoon and Janpui, Luang Chan Aksorn, Jan Meng and Mr. Kumsing-a Laotian who was hired to paint a mural painting at Puttasima temple and Phra That Phanom Chapel entrance when the monk named 'Pra Kaew' was the abbot. From the survey, carved on the stone inscription found inside the temple was the name Jan Sing as the painter of the mural painting. Therefore, it can be said that there are several painters contributing to this temple.

Poe Kum temple, Nam Kum sub-district, That Phanom district, Nakhon Phanom province: Ban Nam Kum community is located at the mouth of Nam Kum river. The river source is in Nong Han, Muang district, Sakon Nakhon province. The river flows $123 \mathrm{~km}$ Southeastward to Kong river in Nam Kum sub-district, That Phanom district, Nakhon Phanom province. Nam Kum river composes of river branches: Bang river, Huai Khaen river and Phung river. In light of the settlement of the community, based on the community history, it is believed that people from Wang Ang Kam town, Sa Pang town migrate to various places to flee from 'Haw War' 
during the reign of Rama V. Many had crossed to the right side of the Kong river (currently Thailand). Some land at the mouth of Nam Kum river which is an autonomous region of Mukdaharn city ruler. Nam Kum river used to serve as border separating Mukdaharn city from Nakhon Phanom city. Many of the families settled there until it became 'Ban Na Kam Kong' village which is an important community rests beside Kong river. Ban Nam Kum community was very developed due to the fact that it is located near the bank of Kong river, making it strategically important in terms of transportation. With strategically favourable position by being situated at the mouth of the river that faces outwards to Kong river, it became the major port in the area. A telegraph from Royal Prince Wattana in 2446 on 13 February indicated that Thailand had made a contract with France, permitting them to build warehouses to house their guns and coals and used Chiang Kong, Nong Khai, Chaiyaburi, Pak Num Kam (Nam Kum river mouth), Mukdaharn, Khemmrat and Pak Mun as their port for the steamers. The Telegraph shows that Pak Nam Kum or Ban Num Kam was indeed an important port used for transportation through Kong river.

Poe Kum temple is an old Mahanikaya sect temple built by people. It used to be Phra Pariyattidhamma School in the past. However, since, education in the country has been developed, none came to attend at this school like they used to. Its role as Pariyattidhamma School was therefore, dissolved. The temple was established in $2418 \mathrm{AD}$ during the reign of Rama V. The mural painting was drawn before $2476 \mathrm{AD}$ and the temple was consecrated in the same year (2476 AD). The temple was named after bodhi tree grew at the foot of Pak Mae Nam Kam bridge. The temple was constructed when Provost Wimondit (Luang Pu Tan) was the abbot who oversaw the construction project with together with following construction counsels to the project: provost Sila Pirat or Ya Tan Mi, the former abbot of Phra That Phanom and the first Ecclesiastical district officer of That Phanom (2458-2479) and Provost Wirote Ratanobol from Tung Sri Muang temple in Ubon Ratchathani. After Luang Pu Tan passed away in 2512 AD, people built him a stupa which houses his bone inside. The stupa was then placed behind the temple. It was built in remembrance of his contributions, especially, for his leadership during the temple was built and the mural painting was completed.

Mural Painting found in Poe Kum temple was built around 2476 AD by Paw Lee Chapran and Mr. Bunpan. Chapran, the brother. The mural painting was completed within over a year. Lee Chapran, the craftsman used to draw mural painting with Luang Cha Aksorn at Hua Wirng Rangsi temple in That Phaom sub-district, That Phanom district, Nakhon Phanom province. Master Lee Chapran was from Ban Nam Kum but was locally from Mukdahan. He had learned the skill of painting once he was ordained as a monk at Poe Kum temple. There he studied with Prajumkhao on how to draw tracery. He later entered monkhood and studied at That Phanom temple and became the pupil of Luang Chan Aksorn. There, he had various opportunities to work alongside with his master, Luang Chan Aksorn, on several occasions: Hua Wieng Rangsi temple, Hor Phakeo, That Phanom temple. He later crossed the river to Laos to draw at different temples and also painted on 'Pra Wet' cloths. At the time, Master Wimonbundit (Luang Pu Tan) was the abbot and oversaw the drawing technique called 'tam-hoop' (Mural paining technique in the Northeastern part of Thailand). The process was also advised by Master Wirote Rattanobol. It is therefore, believed that several painters had contributed to the paintings.

\section{RESULTS AND DISCUSSION}

Widespread of capital culture to local through Master Wirote Rattanobol: The history of the creation of Muang That Phanom mural paintings: mural Paintings which can still be seen nowadays were first drawn in 2462-2477 AD or near the end of Rama VI reign and the beginning of Rama VII reign-the time when the country was transitioning from 'Absolute Monarch' to a democratic country. Such is a phenomenon which concurrent with the concept of 'cultural diffusion'. Likewise, the widespread or the diffusion of Bangkokian mural paintings to Muang That Phanom through a group of artists in Ubon Ratchathani province. The said group played an important role when Master Wirote Rattanobol and Luang Chan Aksorn came to restore That Phanom. This is in line with Patarasuk (2011) who described the influence Master Wirote Rattanobol had on the restoration of Phra That Phanom, since, 2444 AD. During that time, grantors traveled to invite Master Wirote Rattnobol whose title was Master Udon Pitak Kanadej of Tung Sri Muang temple, since, he was specialized in restoring stupa.

Master Wirote Rattnobol possessed notable ability in producing mural paintings of which style had the mixture of the pattern used in the royal court and local artistic sense. This is consistent who described of the mural painting in Tung Srimuang temple in Ubon Ratchathani province that it contains the resemblance of the pattern commonly used in Bangkok during the end of the Rama iv reign until the beginning of Rama $\mathrm{V}$ reign and artistic pattern found when the Phra That Phonom was restored during the time Master Wirote Rattanobol was an abbot (2424-2485 AD). During such restoration by Master Wirote Rattanobol, mural paintings had been improved, adjusted and mixed with local artists' taste. Such change and adjustment were the results of an attempt for the survival of the artwork. This is consistent with Chawalit Atipatayakul (2017a, b) who mentioned the role played by Master Wirote Rattanobol that he was once educated in Bangkok and stayed at an equipment office. There, 
Master Wirote had absorbed the artistry sense of Bangkok. Once he returned to Tung Sri Muang temple in Ubon Ratchathani province, he had an opportunity to work with Luang Chan Aksorn, who had taught his pupil the art of mural painting which was later used with all the 'Sims' of the three temples in Muang That Phanom.

Cultural mixture between capital and local artistry senses: Regarding the relationship of the artists who created mural painting in all three temples, their, expressions are interrelated in that all mural paintings' styles are the mixture of the capital and that of a local. The chief artists who drew mural painting at Hua Wieng Rangsi are Luang Chan Aksorn who was the standout pupil of Master Wirote Rattanobol. Therefore, it was inevitable for him to possessed cultural diffusion concept in light of mural painting-passing on painting style used in this temple to his other artistry pieces. In the same regard, though Puttasima temple's mural paintings were created at around the same time, though the style expressed through the work was that of a local artist like Mr. Kamsing, there is still a mixture of capital artistry style which Luang Chan Aksorn and his pupils from Hua Wieng temple used. As for Poe Kum temple, the abbot who was Master Wimon Bundit (Luang Paw Kum Tun) was also then the key pupil of Master Wirote Rattanobol back when Pra That Phanom was being restored. Though Master Wirote Rattanobol had gone back to Ubon Ratchathani, Master Wimon Bundit still constantly received affection from Master Wirote Rattanobol. Such was evident when the coin relic was made with Luang Poo Tun's (Master Wimon Bundit) name on it. The relic coin was made in approximately 2483 AD and is now very rare. Luang Poo Rod or Master Wirote Rattnobol had ordered the coin to be made to celebrate the monk's rank of Luang Poo Tun or Master Wimon Bundit. In the front of the coin is the portrait of Luang Poo Tun and in the back is the picture of Master Wirote Rattanobol. Such is the evidence that mural painting in Siam was strongly influenced by Master Wirote Rattanobol.

The influence of Bangkok mural pattern diffusion which was passed on to other places through the border city like Ubon Ratchathani had influenced local art. This is consistent with a study conducted by Green (2011). Her title of the study is 'from Gold leaf to Buddhist scripture'. The study summarizes that the relation to the eastern region which was found in the Burmese mural painting in the later era was influenced by Thai mural painting. In 1767 AD, Burmese army invaded Krung Sri Ayudhaya and had brought with them Thai prisoners to the central of Burma. Among the prisoners were artists and actors. It is believed that this was the beginning that Thai art started to influence Burmese art, including their mural paintings. Saisingha (2012) also describes the mural paintings in Laos that mural paintings can be commonly found on the walls of the temple's Sims (main halls), chapel, temple repository for the Buddhist scriptures and the hall for the people to pay respect to the Buddha image. He explained that the mural paintings on those walls are like those which can be found in Thai mural painting. It was found that the fine art evidence of Laos which are antique mural paintings were drawn in Thai Rattanakosin era (Rama III and Rama IV). Examples are mural paintings on walls discovered in the main hall of Sisaket temple in Vientiane, Siputtabad temple, Pa Huak temple, Long Koon temple in Vientiane, etc. These mural paintings can be divided into 3 groups based on the received influence in different eras: Ratanakosin influence (during the end of 24th BE to the mid-25th BE), local style (the end of 24-25th BE) and the current style (since the 26th BE) (Saisingha, 2012). From the discussion above, it can be seen that the diffusion of mural painting styles of Bangkok influences directly and indirectly to border cities and colonial cities. Depending on the local border cities, they could choose to adopt the style or adapt by adjusting it to be in harmony with the community's tradition and cultures. In the case of mural painting of That Phanom, the community both adopt and adapt the influence they received to make it consistent with their local community.

Cultural mixture through artistry and literary expression: Though the administration regime of Isaan had long been changed from 'A-ya Si' (Four Administration Unit Regime) to Thesapibal Regime and to Absolute Monarchy, artistry influences they received from Siam were usually partial. Most would be adjusted and mixed either in its pattern or the content to make it harmonize with their own local art. In the case of Hua Wieng Rangsi temple, though Ramayana is included in their mural paintings like that of the ones in Bangkok, a lot of the paintings are still about the 10 last Jatakas which is more popular in Isaan region. As for Poe Kum temple, included in their art work is local literary work such as 'Suriwong' which took up as much space as the story of the Buddha did. In the case of Phuttasima temple, local literature being told through their paintings called 'Sinsai' of which portion is about the same as that of the '10 Last Jatakas'. Intertwined in these artistry pieces are also the villagers' livelihood that was illustrated on the wall. These adaptation and adjustment are consistent with Saisingha (2017), who presents the influence of Siamese fine arts on Luang Prabang artistry work during the time when Siam ruled over Luang Prabang. The study was conducted on the mural painting of which story is about 'Chompoobodi Sutre' in Pbaa Louak temple (Pbaa Huak), it was found that the pattern, principle and reflection of Luang Prabang people in Laos that though the 'Chompoobodi Sutre' mural painting in Luang Prabang was created by mimicking Na Nong temple's mural painting about the great emperor that Rama III 
created inside the main hall, Laos' drawing in Pbaa Louak temple also included in the artwork Laos' social way of life and culture.

In other cases of Phuttasima temple which were built after the regime was changed, the temple did not adopt the whole distinctive character of mural painting in their artwork. They instead used local literature called 'Suriwong' as their main story in the mural painting. This is in line with Singsuwan's (2014) study. The role of politics on social's national state from 2475-2500 BE places much importance on the people who are an essential element to the state. This has drawn Isaan people to mobilize political and cultural movements based on their 'Localism Consciousness' principle. Culturally, nationalism in the region has become more widespread. It has encouraged Isaan people to learn more about their own background and present their local historical identity. This is an attempt of Isaan people in bargaining for and adapting to be more recognizable as 'part of the nation' in the new political system.

Isaan people's adaptation to be more recognizable as 'part of the nation' in the new political system is evident in mural painting which tells the story about the Buddha or Pathamasambodhis or Pathomsompoj as written in Laotian on the ancient palm leaf manuscripts. The said mural painting was on the wall behind the main Buddha image in Phuttasima temple. However, in Hua Wieng Rangsi, it was found on the opposite side of the main Buddha image. In Poe Kum temple, most of the mural paintings were drawn most wall to the right of the main Buddha image. Though the three mural paintings are in the same area, how 'Pathomsompoj' was drawn is highly independent. This contradicts with the research study of nongnuch Phoomalee (2016). In the study, the researcher mentioned about illustrations of story of the Buddha found in Ban Nua Khon Kaen temple in Roi Et province, in that though skills and knowledge have been locally passed on to the local artists through kinship, it doesn't mean that the paintings used in religious art are completely independent of each other or disorderly done. The study on mural paintings in That Phanom, the results of the study says otherwise-each work is independent of each other. Such is consistent with Atipatayakul (2012a, b) who said that if look at the work superficially, one might find that the artists did not follow any rules or regulations in regard to placement of mural paintings. However, if the works are perceived from the different point of view, one might find that it is rather the reflection of the artists' tastes. The artists create their pieces with the craftsmanship they have more abundantly than other laymen. As a result, each artistry piece with different locality would express their differences in tastes and layouts. This is consistent with Songmek (1995) who study cultural integration between Bangkok and Lanna in mural painting during the reign of Rama V.Mural Paintings inside Bod Manee Sriboon-Roeng temple was influenced by moral precepts, beliefs, techniques and forms they received form the central of Thailand. Nevertheless, partial adjustments was applied to make the drawing correspond with the artist's taste, that is by adding illustrations which show the livelihood of Tak people. This has made the main story became distinct. Some adjustments were applied to reflects the local's artistry tastes. The mural paintings are therefore, independent in terms of the chosen story, spaces used for the illustrations, the position of the painting and forms of their expression.

Saiphan (2016) stated that if analyzed through cultural-social context during the reign of Rama VI, it is found that the Siam's center of power was Bangkok. They positioned themselves as 'the owner of the country' by hosting the restoration of Phra That Phanom to let Laotian in both Laos and Siam including people of mixed blood between Thai-Laos who are citizens of Siam residing near Kong river acknowledge the position of the central. Therefore, in each restoration, a group of artists would be assigned by the king-the center of power in the Absolute Monarchy regime-to take up their duty as the 'artists' who were directly appointed by the king. Sometimes they would be called 'Chang Luang' (chief artists) of the local people. The word conveys a different sense in meaning from the word 'Chang Luang Haeng Ratchasumnak' (chief artist of the royal court) who is considered one with the highest knowledge as an artist of the state-royal court artist.

In light of mural paintings found on the wall of Hua Wieng Rangsi and Poe Kam temples in Ban Na Kum, though Luang Chang Aksorn-referred to as 'Chang Luang' by the local people-took part in the drawing, the painting in Hua Wieng Rangsi still reflects the primitive mural tradition in the deepest part of Isaan region which located along the border between Siam and Laos which was at the time the colonial country of France. A similar case can be seen in Taku temple in Nakhon Ratchasima Province locating along the margin of the Siam Empire and Lancang Empire in the context of the traditional state. This region had later become Isaan.

Politics and religion in Isaan through Thammayutanigai: In the case of Sim of Hua Wieng Rangsi temple which is a Thammayutanigai temple, it was influenced by Sim in the Southern Isaan. The researcher presumed that the influence stemmed from the desire to diffuse the sense of Siam sate to the region gradually with the help of Thammayutanigai. Tongklom (2013) conducts a study on Thammayutanugai temples in Ubon Ratchathani and found that the main hall is considered the most important architecture in Thammayutamigai temple in Ubon Ratchathani. The main hall will usually be in the center of the temple. The building is decorated with Tympanum which looks like stupa or bell. The tympanum 
is not decorated with gables but will be adorned with decorating features called 'Lamyong' which are carved into different forms such as Naka body, the curved, hangsang and Naka head. Thammayutanigai temple in Ubon Ratchathani can be divided into 3 ears. The 1st era refers to the time when the temple was established in 2394-2452 BE during the reign of Rama IV and V-the time when Thammayutanigai was widespread in Isaan to create unity in the empire. Thammayatanigai originated in Ubon Ratchathani province in Isaan. The architecture of Thammayutanigai temple in Ubon Ratchathani was popular locally and people were united. For this reason, this new cult was easily embraced by the local people. The 2nd era was in 2453-2480 BE during the reign of Rama VI until the reign of Rama VIII. In this era, Thammyutanigai temple's identity became more apparent in terms of architectural feature in Ubon Ratchathani province. This reflects that Thatyutinigai became more solidified. It also acted as religious and political leaders that follow the policy of the state. The 3rd era started in 2481 BE since, the day of General Por Pibul Songkram until the present. In this era, the main hall of the temples looks like the hall which can be commonly seen in the central of Thailand. The difference can be seen in some details of the main hall of 'Wat Supattanaram Worawihan'-the symbol of Thamayutabigai temple in Isaan. This implies that the unity of the central empire became more solidify, the monastic order of Thammyutinigai became less significant.

Therefore, forms of Sim (main hall) in Hua Wieng Rangsi temple resembles Sim in the southern part of Isaan, especially, the monk's seat which raised up a little bit higher from the floor. The plaster base for Buddha image was separated from the wall of the main hall. These are the difference which can not be found in Puttasima and Poe Kum temples. Both temples do not have raised seat for monks and plaster base for Buddha image was built attached to the wall on the opposite side of Sankom (2015) or the main hall's entrance. Such is consistent with who described how Thammayutinigai under Monk Wachirayan-pikku became widespread. After Monk Wachirayan-pikku established Thammayutinigai, several men came to enter the sect as followers. Thammayutinigai belief then became prosperous in various border cities. From the border city of Laos (currently the Northeastern Thailand), Phra Ajarn Panatulo (Dee) and Phra Ajarn Te-Watammee (Mow) who were the followers of Monk Wachirayan-pikku came to spread the religion in Ubon Ratchathani, their hometown. They also built Wat Supattanaram Worawihan which they later anointed it as the first temple under Thammayutinigai sect in the border town-Laos. Once the number of Thammayutinigai followers grew larger, the religion became more widespread to the cities nearby. Later, during the reign of
King Rama V, the King had ordered that local administration system in the country be revolutionized by dividing administration areas into Monthon Thesapibal one Thesapibal was divided into several Monthons in the border city of Laos. One of the Monthons was 'Monthon Udon' which was changed from 'Monthon Lao Puan'. In 2436 BE, 6 cities which were under the administration were: Udon Thani, Khon Kaen, Sakon Nakhon, Loei and Nong Khai. Therefore, the widespread of Thammayutinigai had brought with them the architectural style of Sim from Southern Isaan or Sim from Monthon Isaan to That Phanom with them. Saiphan (2016) replicated that the adjustment made with an attempt to centralize the Buddhism belief had critically affected Buddhism belief in the local. One regulation was promulgated; it stated that before monks can be accepted or certified, the person to be ordained as monk shall not have tattoos on his face and shall not be ordained before more than 3 times, etc. The dissolution of traditional belief which intertwined with the precepts of spirits and Brahmin integrated with the Buddhism belief, especially, the reorganization of monastic order had made the role and the concept of Thammayutinigai-the representative from the central-became more meaningful. Such change had driven local Buddhism practice to be adjusted. Promotion of monkhood rank to 'Sa' and 'Koo' based on a local tradition called 'Hod Song' and 'Sangha Act of 1941 (Ror Sor 121)’ was dissolute. Such were the results of the religious revolution when 'Somdej Mahawirawong was the ecclesiastical provincial Governor Monthon Isaan. Such was the time where concepts and religious practices had been dramatically changed and centralized. Here was the beginning of the relationship between religion and politics. Buddhism was used by the state to draw in local to the central as well as enforcing new administration mechanism and ideology of nationality. This is consistent with the study conducted by Puchidchawakorn (2014). The study reveals development and change of Lancang ordination and wihara halls (temples) in Isaan region can be divided into 5 periods. During the first period, Lancnag Empire still ruled over Isaan region. Therefore, the construction of Lancang ordination and wihara halls was influenced by Vientiane-Lancang Empire. It can be said that it was built in the style called 'Sakun Chang Lancang'. The second period was when the power of Lancang Empire started to deteriorate. The construction of temples in Isaan region had been adjusted to the 'local context'. There seems to be more independence in this period, since, artists were allowed to use existing materials. This is the period where the society was stepping into the style called 'Sakun Chang Thai-Isaan' which was based on the architecture concept called 'Local Issan Sim'. The third period happened during the reign of King Rama IV. Since, the 
reign of Rama IV, many changes had taken place due to numbers of factor which include the invasion of France and migration of Vietnamese people (Yuan). This had resulted in applied architecture called 'Local applied Sim' which can be divided into sub-categories: 'Isaan Applied Sim' and 'Yuan/Vietnamese Applied Sim'. The fourth period was when General Por Pibulsongkram and Fine Arts Department created a prototype Sim. With better infrastructure-improved railway, influence from the central in fluxed into Isaan region. Sim was built with the 'mixture of central and local style'. The last period is in the current reign. Old Sims start to deteriorate. Conserving the Sims was not easy since values hold by Isaan people had changed and the fact that communities are growing larger. In this period, old Sims have been torn down and replaced with the 'new temple with common style found in the central of Thailand'.

Nevertheless, the researcher believes that the construction of Sims can also be affected by political factors as well. When Muang That Phanom acknowledged of such relationship (between politics and Sim's architectural forms), it attempts to maintain its social status by bringing in its local culture and make any necessary adjustments that are in agreement with religious and country's administrative ideologies-it started by adjusting the said relationship by giving Sim the design which is both localized and centralized that possesses Siamese state design.

Literary works in mural paintings: Aesthetic stories of literary works are used to convey religious meaning and communicate religious and state administrative ideologies. Literary works which appear on the mural paintings composes of canon literature and peripheral literature. Canon literatures are used to convey religious meaning through the core idea of each story while peripheral literature, especially, Ramayana story, the capture of ramayana, Chantakorab, Lucksanawong and King Saud thon-manohra are expressed aesthetically to reflect religious and state administrative ideologies through the symbolic use in the mural painting. Appear in the paintings of Hua Wieng Rangsi and Puttasima temples are Siamese flag-white elephant in the middle with red background; king Rama IV thought that the red flag people commonly used was the same as the other national flags. He, therefore, ordered that a white elephant be placed in the middle of the flag. The flag was then used as Siamese flag until King Rama VI era. In BE 2549, the government declared in the Flag Act RS 129, stipulating that the flag shall have red background with white elephant wearing armor and looking straight at the flagpole (TNIO., 2011). Having flags drawn in the mural painting was the declaration that Muang That Phanom was now part of the Siamese state, so as to correspond to the call of Siam Royal Court that 'the nation' be built and solidified. Nevertheless, the way to make local artwork survive is to adjust and be dynamic to the changes-because in any circumstances, printed on those mural paintings, one will always see the ways of life of Isaan people there.

During the breakthrough, though mural paintings of That Phanom had integrated into its drawing the local artistry and that of the Siamese state, the influence (of Siamese State) became gradually less intense. This is consistent with Atipatayakul (2012a, b), who stated that Isaan mural paintings are usually drawn inside and outside of the temple's main hall or Sim. This special technique they used was passed on to them from Lao PDR. However such technique has limitation in terms of the colors use. Because of this limitation, the color of the skins is usually left out, untarnished as can be seen in the pictures. The first phase was the integration between central style-form of prototypes for the local artists to follow-and Isaan artistry style. The second phase is the phase the local artists beautifully expressed themselves through their distinct techniques. And the last phase is the combination of various stories and placements of the paintings. In this phase, central painting style has again become somewhat influential to the paintings in terms of the dimension used in paintings to indicate the distance of the objects. This technique the central learned was originated from the western world. Pop culture literature; From Siamese State to Muang
That Phanom mural paintings: Peripheral literature in That Phanom mural painting are Bangkok's pop culture literature which later spread to other regions. Popularity is probably the key factor that these works of literature were included in the mural paintings. Examples of these literature are Ramayana in Hua Wieng Rangsi, Puttasima and Poe Kum temples; Chantakorob and King Saud thon-manohra in mural paintings of Puttasima temple and Lucksanawong in Hua Wieng Rangsi temple. These literatures weren't the main focus in the mural painting. The researcher assumed that the said literatures weren't popular in local culture but favorable to the people in Bangkok. This is consistent with Yoo-in (2013), who delved into the popular literature in Bangkok, especially, in printed media since BE 2378 during the reign of King Rama III. This period was the era where modern printing from the western world entered the country. The key figure who played an important in the printing media was Dr. Dan Beach Bradley, an American Missionary who brought in the first printing machine and Thai types from Singapore in BE 2378. Many printing houses sprung up during this period such as Bradley Printing House, Dr. Smith Printing House, Ratcharoen or Wat Kaw Printing House, Hang Samut Printing House, etc. Printing 
houses which played such an important to Thai folktale books are Dr. Smith and Ratcharoen Prining Houses. Many of the Thai fairytales or folklore tales were also printed by other printing houses which was established around the same time as Ratcharoen Printing House such as Dr. Smith Printing House, Nai Sin Printing House, Nai Tep Printing House and Panichsappaudom Printing House. It was found that peripheral literature seen in the mural painting of That Phanom were popular among the people and were published by numerous printing houses such as Lucksanawong and Chantakorob. Moreover, the story which was poplar for the play performed by all females (Lakorn Nai) was 'Ramayana'. As for the stories used in the play performed by all males (Lakorn Nork) include Laucksanawong, Chantakorob and Ramayana. As for the popular books which were adapted into plays were Lucksanawong and Chantakorob. Lucksanawong was also commonly used in rod puppet show as well. 'Pleang Song Kruang', a kind of play originated during the reign of King Rama V, usually used Lucksanawong and Chantakarob in the play. 'Talung' a kind of entertain popular in the central of Siam during King Rama V reign. Stories used in 'Talung' was Ramayana including other stories such as Lucksanawong in the later period. It is possible that peripheral literature were popular in Bangkok before their popularity reached Muang That Phanom. People who played important roles in the creation of mural painting in That Phanom, for example, Master Wirote Ratanobol and Luang Chan Aksorn were all aware of and understand the central pop culture.

In the case of the literary story of Siam's 'Lucksanawong' and Suriyawong which were included in That Phanom Mural Paintings, The Princess Maha Chakri Sirindhorn Anthropology Centre (Public Organization) (online) stated that Lucksanawong is a literature in Ratanakosin era (King Rama III) composed by Sunthorn Phu, Thai legendary poet and writer (Anonymous, 2017). OLH. (2015) also stated that the tales 'Lucksanawong' was written by Sunthorn Phu and was composed during the reign of King Rama III. Lucksanawong is a poem of which story and aesthetics are highly valuable. It was written with a great plot and was able to touch its reader. It has been one of many pieces of literature which embedded in the hearts of many of its audience. The only scene of Laucksanawong drawn in the mural painting in Hua Wieng Rangsi temple is the scene when Pra Lucksanawong is devouring Kinnara. Lucksanawong also reflects people's belief in destined wife or husband, worshipping or praying to the holy creatures or spirits to help and protect them or to be a witness to them. It also tells about people's belief in dreams, dream prophecy and fortune telling. The story is intertwined with Thai people's traditions in the past. Looking at the content of the literature 'Lucksanawong' by Sunthorn Phu, the storyline does resemble with 'Suriwong' which was written in the mural painting at Poe Kam temple in Nam Kum sub-district. Therefore, it can be said that though Lucksanawong was popular in Siam but That Phanom people chose Suriyawong over Luksanawong which has the same storyline due to 'their favor for local culture'.

\section{CONCLUSION}

History: From an examination on the history of the creation of the wall mural painting of Muang That Phanom in Nakhon Phanom province, it was found that That Phanom mural painting in Nakhon Phanom province was first drawn between 2462-2477 AD near the end of the reign of Rama VI until the beginning of Rama VII. This is the country's transition period from absolute regime to a democratic country. Appear in the mural painting found in the three temples are key political events.

'Sims' or main halls of Hua Wieng Rangsi and Phuttasima temples were built in 2460 AD. The temples were consecrated the same year in 2462 AD. Mural paintings were first drawn at Hua Wieng Rangsi temple in 2462 AD. and Puutasima temple in 2463 AD. The period when the paintings were created was around the same time-from 2453 until 2468 AD. during the reign of Rama VI-by the same group of artists.

'Sim' in Poe Kam temple was built in 2476 AD. and the mural painting was painted during 2476-2477 AD. The time when mural paintings were first painted in Hua Wieng Rangsi temple is around 14-15 years apart when Phuttasima temple have their walls decorated with the mural art.

Temples in Muang That Phanom with mural paintings include the temples surrounding That Phanom Stupa and That Phanom temple itself. These temples are considered vital in light of monastery administration and education of monks in the area. Nevertheless, Poe Kum temple in Northern Ban Na Kum and Phuttasima temple in Ban Fang Daeng are also significant to both large and old communities. The reason is that both Ban Na Kum and Ban Fang Daeng are considered important, since, they settled around That Phanom Stupa and received influence from artistry work which was used during the restoration of Phra That Phanom. They have especially, adsorbed creativity expressed through mural paintings created by Luang Chan Aksorn and his pupils in Hua Wieng Rangsi temple. It can be said that this group of artists had brought with them a sense of art from Bangkok and passed it on to border cities in Isaan region. Such was evident, especially in artistry concept of Phra Kru Wirote Rattanobol, the master from Tung Sri Muang temple in Ubon Ratchathani province. It is apparent that the mural painting style in Bangkok was very influential to the mural paintings found 
in Hua Wieng Rangsi temple. Regarding Phuttasima temple, the name Master Kam Sing was carved as evidence that he was the key painter contributing to the creation of mural paintings in Phuttasima temple. Though it contains less of a Bangkokian artistry sense, it still somehow influenced by the painting style used in Hua Wieng Rangsi temple. The painting styles in Poe Kum temple, however are found to contain both Bangkokian and the local artistry sense.

The widespread of Bangkokian mural painting style did not come directly from the Master Luang Aksorn. Such painting style was passed on to the artists in Isaan indirectly through, the artists from Ubol Ratchathani province. The mural painting styles in the area were therefore, mixed with the local artistry sense as well. Moreover, the transition of styles also happened at the national level. Artists from Laos were hired to paint with the technique called 'tam hoop' in Siam. From the study, it was found that all mural paintings in Muang Phra That Phanom were originated from the restoration of Phra That Phanom during the high time of Master Wirote Rattanobol from Ubon Ratchathani and Luang Chan Aksorn as the master of painting. Together, they had brought Bangkokian mural painting style to the local mural paintings found in Phuttasima and Poe Kum temples.

\section{REFERENCES}

Anonymous, 2017. Thai Literature Directory. The Princess Maha Chakri Sirindhorn Anthropology Centre, Bangkok, Thailand.

Atipatayakul, C., 2012a. Hoop Tam in Isaan: Historical Perspective on Local Fine Arts in Isaan. Tao-Low Printing House, Udon Thani Province, Thailand,.

Atipatayakul, C., 2012b. Layout of temples and Ubosots in Thailand in Relation to Sims in Isaan. Rajabhat Maha Sarakam University, Maha Sarakham, Talat, Thailand,.

Atipatayakul, C., 2017a. Report on academic seminar: Isaan mural paintings-looking through lens in people of Isaan and the central of Thailand. Northeastern Thai Buddhist Art and Culture Learning Centre, Udon Thani Rajabhat University, Udon Thani, Thailand.

Atipatayakul, C., 2017b. Report on academic seminar: Isaan mural paintings-looking through lens in people of Isaan and the central of Thailand. Northeastern Thai Buddhist Art and Culture Learning Centre, Udon Thani Rajabhat University, Udon Thani, Thailand.

Boonlop, K., 2005. Traces of Ancient Khmer Culture in Sakon Nakhon Basin. 39th Edn., Princess Maha Chakri Sirindhorn Anthropology Centre, Bangkok, Thailand,.
CDA. and Archive, 1999. Culture and Development of History, Identity and Local Wisdom in Nakhon Phanom Province. Kurusapa Ladprao Printing Press, Bangkok, Thailand,.

DRA., 1996. History of temples in the Country. Vol. 15, Kansatsana Printing House, Bangkok, Thailand,.

GISTDA., 2010. Photobook: Map of Thailand from Satellite. Amarin Printing and Publishing, Geo-Informatics and Space Technology Development Agency (Public Organization, Bangkok, Thailand,.

Green, A., 2011. From gold leaf to Buddhist hagiographies: Contact with regions to the east seen in late Burmese murals. J. Burma Stud., 15: 305-358.

OLH., 2015. Sunthorn Phu's Poetic Story: Lucksanawong. 4th Edn., Department of Fine Arts, Office of Literature and History, Bangkok, Thailand,.

Patarasuk, U., 2011. The study of phra that Phanom influence on beliefs and rituals of Mekong Basin community. Master Thesis, Mahachulalongkornrajavidyalaya University, Bangkok, Thailand.

Phoomalee, N., 2016. Mural paintings by local artists in central Isaan. Silpakorn University, Bangkok, Thailand.

Puchidchawakorn, T., 2014. Lancang temples-summary of form, characteristics, development and change. NAJUA. Mag., 11: 274-3045.

Punnothok, T., 1988. Importance of Isaan stone inscriptions in Thai-laos Era: Historical facts in a decade (BE 2520-2530). Citizen Watch Company, Bangkok, Thailand.

Saiphan, P., 2016. Buddhism and political identity of Phuthai Ethnic in the Northeastern Thailand. J. Soc. Anthropol., 2: 47-71.

Saisingha, S., 2012. Pagoda, Buddha Image, Hoop Tam, SIM and Lao and Isan Art. Museum Press, Nonthaburi, Thailand,.

Saisingha, S., 2017. The Mural Painting of Chomphu Bodhi Sutre in Pbaa Luak temple (Pa Huak): Creation Principle and Reflection of Lao Society in Luang Prabang. Museum Press, Bangkok, Thailand,.

Samosorn, P., 1989. Isaan Mural Painting. Amarin Printing Group, Bangkok, Thailand,.

Sankom, T., 2015. Mahachai temple: The first Thammayutinigai temple in Monthon Udon. J. Way Hum. Soc., 2: 65-84.

Singsuwan, A., 2014. Social change and the formation of local consciousness of Isaan people from B.E. 2475 to 2500 in Prea-wa Klasin. Acad. J. Kalasin Univ., 1: 9-30.

Songmek, S., 1995. Mural painting in Manee Sribunroeng temple in Tak Province: Integration of Bangkok and Lanna culture during the reign of King Rama V. Master Thesis, Silpakorn University, Bangkok, Thailand. 
TNIO., 2011. Trirong Thamrongthai Handbook. 2nd Edn., Office of the Permanent Secretary, Prime Minister Office, Bangkok, Thailand,.

Tongklom, S., 2013. Research study on thammayutinigai temple in Ubon Ratchathani Province. Master's Thesis, Silpakorn University, Bangkok, Thailand.
Walliphodom, S., 1995. Isaan Civilization Basin. Matichon Publishing House, Bangkok, Thailand,.

Yoo-in, N., 2013. Research on Thai folktales to fantasy films in Thailand.Thai Film Archive, Phutthamonthon, Nakhon Pathom, Thailand. Thai Film Archive, Phutthamonthon, Nakhon Pathom, Thailand. 